\title{
Regioselective Cp*Ir(III)-catalyzed Allylic C-H Sulfamidation of Allylbenzene Derivatives
}

\author{
Amaan M. Kazerouni, ${ }^{\dagger}$ Taylor A. F. Nelson, ${ }^{\dagger}$ Steven W. Chen, Kimberly R. Sharp, and Simon B. Blakey* \\ Department of Chemistry, Emory University, Atlanta, GA 30322, United States \\ ${ }^{\dagger}$ These authors contributed equally to this work. \\ email: sblakey@emory.edu
}

\section{Table of Contents}

Optimization of linear-selective tosylamidation of terminal olefins 


\section{Optimization of linear-selective tosylamidation of terminal olefins ${ }^{a}$}

Under first generation conditions $\left(\mathrm{TsNH}_{2} \text { (2.5 equiv), } \mathrm{AgOAc} \text { (2.1 equiv), [ } \mathrm{Cp}^{*} \mathrm{RhCl}_{2}\right]_{2}(2 \mathrm{~mol} \%), \mathrm{AgBF}_{4}(8 \mathrm{~mol} \%)$, DCE $\left.(0.2 \mathrm{M}), 40{ }^{\circ} \mathrm{C}, 24 \mathrm{~h}\right)$, the linear-selective tosylamidation of allylbenzene proceeded in $40 \%$ yield. A brief optimization of this reaction is reported.

\begin{tabular}{|c|c|c|c|c|}
\hline \multirow{2}{*}{\multicolumn{3}{|c|}{$\begin{array}{c}\mathrm{TsNH}_{2}(2.5 \text { equiv) } \\
\mathrm{AgOAc}^{2}(2.1 \text { equiv) } \\
{\left[\mathrm{Cp}^{*} \mathrm{RhCl}_{2}\right]_{2}(2 \mathrm{~mol} \%)} \\
\mathrm{Ag}(\mathrm{l}) \text { salt }(8 \mathrm{~mol} \%) \\
\text { Solvent }(0.2 \mathrm{M}) \\
\text { temp. }\left({ }^{\circ} \mathrm{C}\right), 24 \mathrm{~h}\end{array}$}} & \multirow{2}{*}{\multicolumn{2}{|c|}{ 3a }} \\
\hline & & & & \\
\hline entry & $\operatorname{Ag}(\mathrm{I})(8 \mathrm{~mol} \%$ & solvent & temp $\left({ }^{\circ} \mathrm{C}\right)$ & $\%$ yield (3) \\
\hline 1 & $\mathrm{AgBF}_{4}$ & DCE & 60 & 61 \\
\hline 2 & $\mathrm{AgBF}_{4}$ & DCE & 80 & 62 \\
\hline 3 & $\mathrm{AgSbF}_{6}$ & DCE & 80 & 29 \\
\hline 4 & $\mathrm{AgNTf}_{2}$ & DCE & 80 & 55 \\
\hline 5 & $\mathrm{AgBAr}_{4}{ }_{4}$ & DCE & 80 & 15 \\
\hline 6 & $\mathrm{AgBF}_{4}$ & DCM & 40 & 46 \\
\hline 7 & $\mathrm{AgBF}_{4}$ & THF & 60 & 70 \\
\hline 8 & $\mathrm{AgBF}_{4}$ & TFT & 80 & 35 \\
\hline 9 & $\mathrm{AgBF}_{4}$ & TFT & 100 & 70 \\
\hline 10 & $\mathrm{AgBF}_{4}$ & $\mathrm{PhCl}$ & 80 & 72 \\
\hline 11 & $\mathrm{AgBF}_{4}$ & $\mathrm{PhCl}$ & 100 & 67 \\
\hline 12 & $\mathrm{AgBF}_{4}$ & 1,4-dioxane & 80 & 64 \\
\hline 13 & $\mathrm{AgBF}_{4}$ & 1,4-dioxane & 100 & 81 \\
\hline
\end{tabular}

${ }^{a}$ Yields were measured by integration against nonane as an internal GC standard. 
${ }^{1} \mathrm{H} \mathrm{NMR}\left(\mathrm{CDCl}_{3}, 600 \mathrm{MHz}\right)$

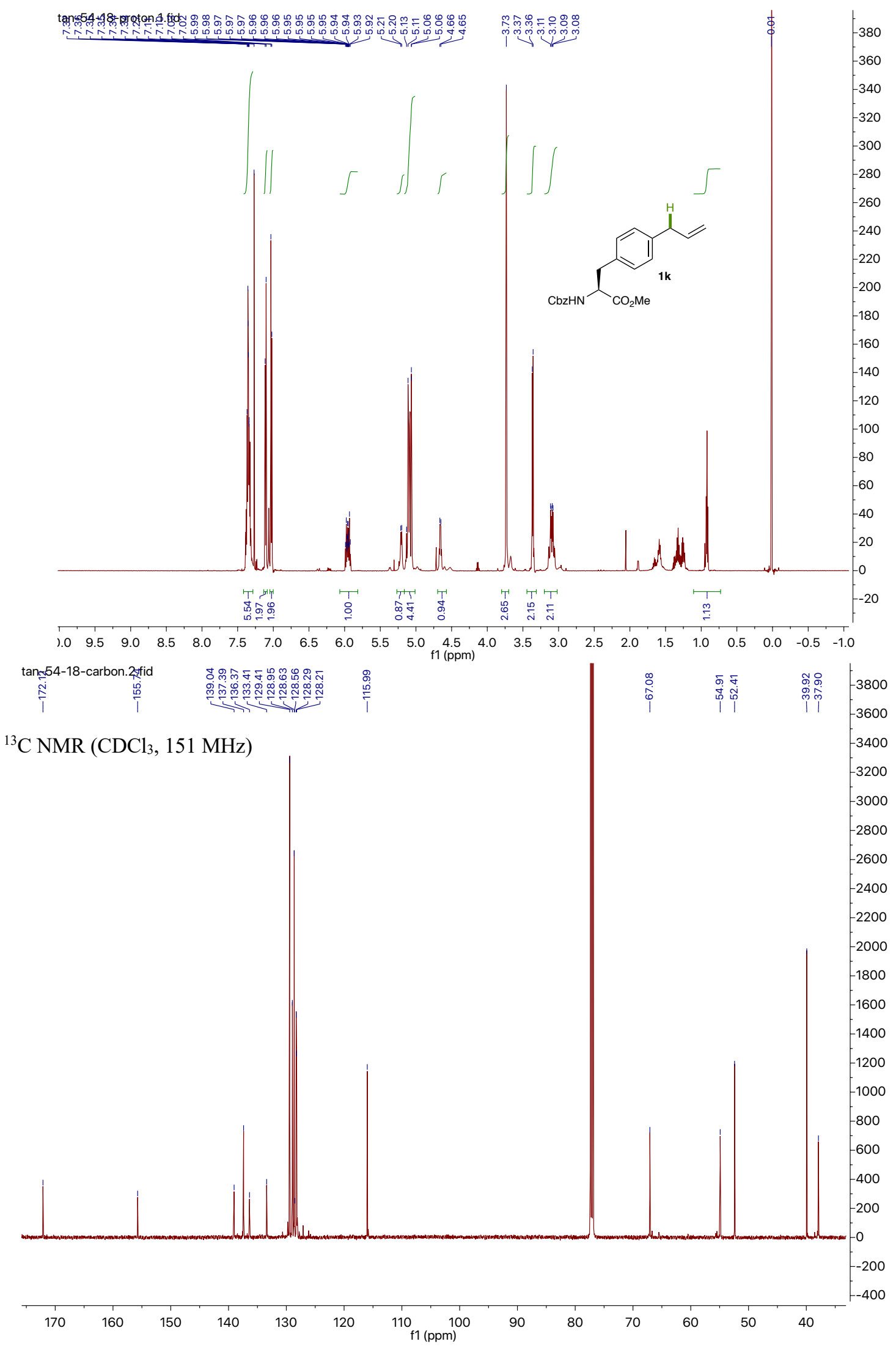


${ }^{1} \mathrm{H} \mathrm{NMR}\left(\mathrm{CDCl}_{3}, 500 \mathrm{MHz}\right)$

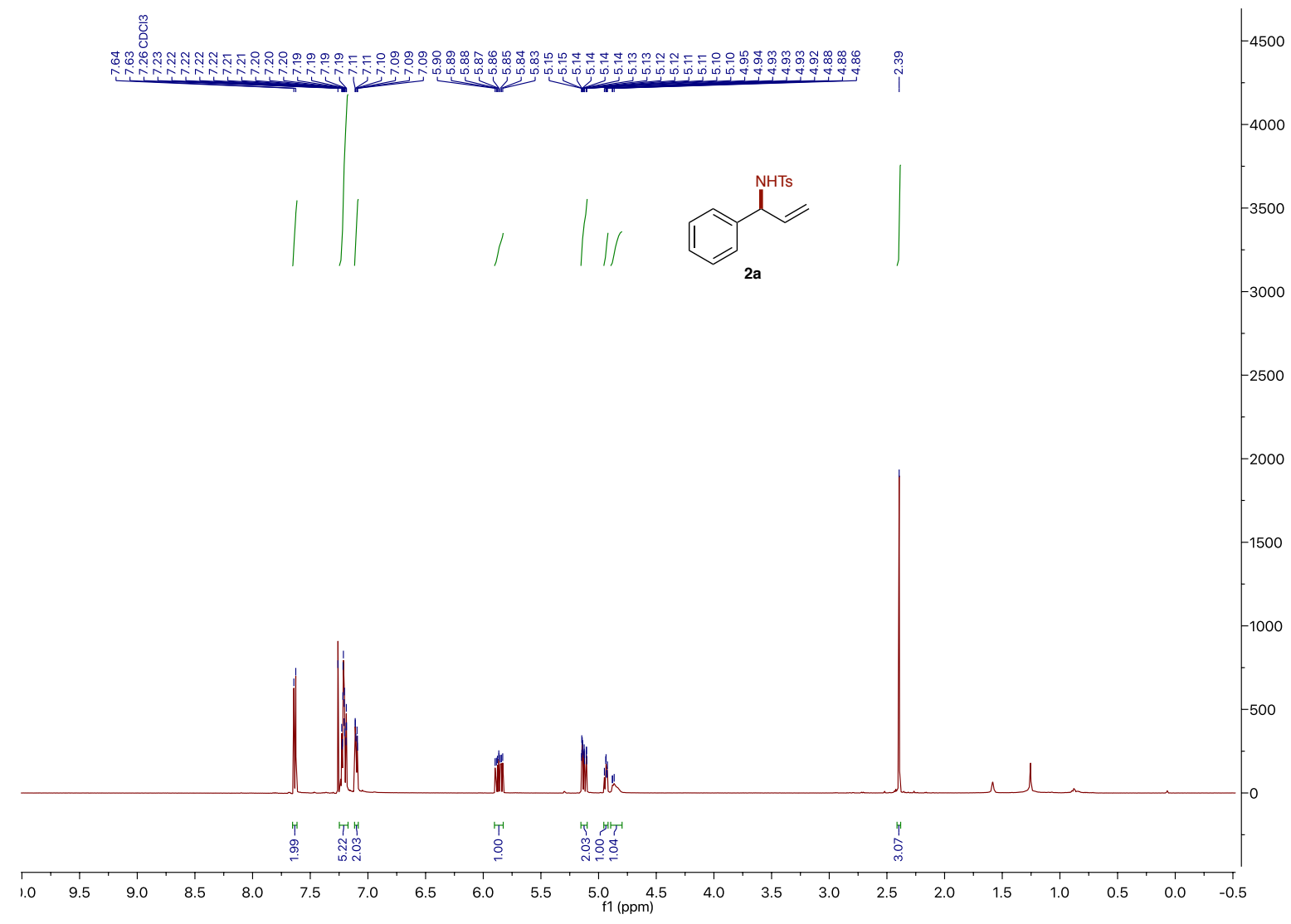


${ }^{1} \mathrm{H} \mathrm{NMR}\left(\mathrm{CDCl}_{3}, 400 \mathrm{MHz}\right)$

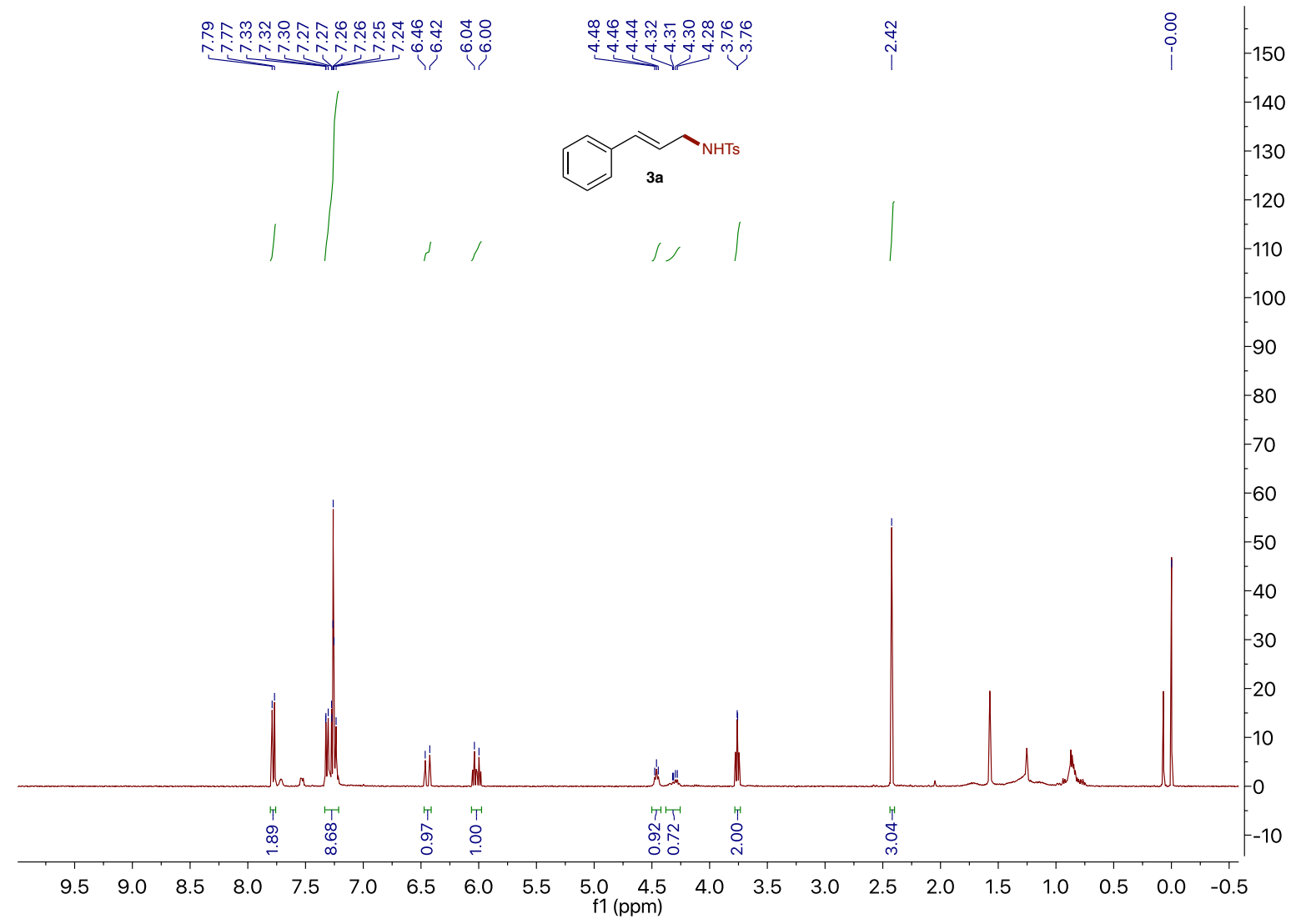


${ }^{1} \mathrm{H} \mathrm{NMR}\left(\mathrm{CDCl}_{3}, 500 \mathrm{MHz}\right)$

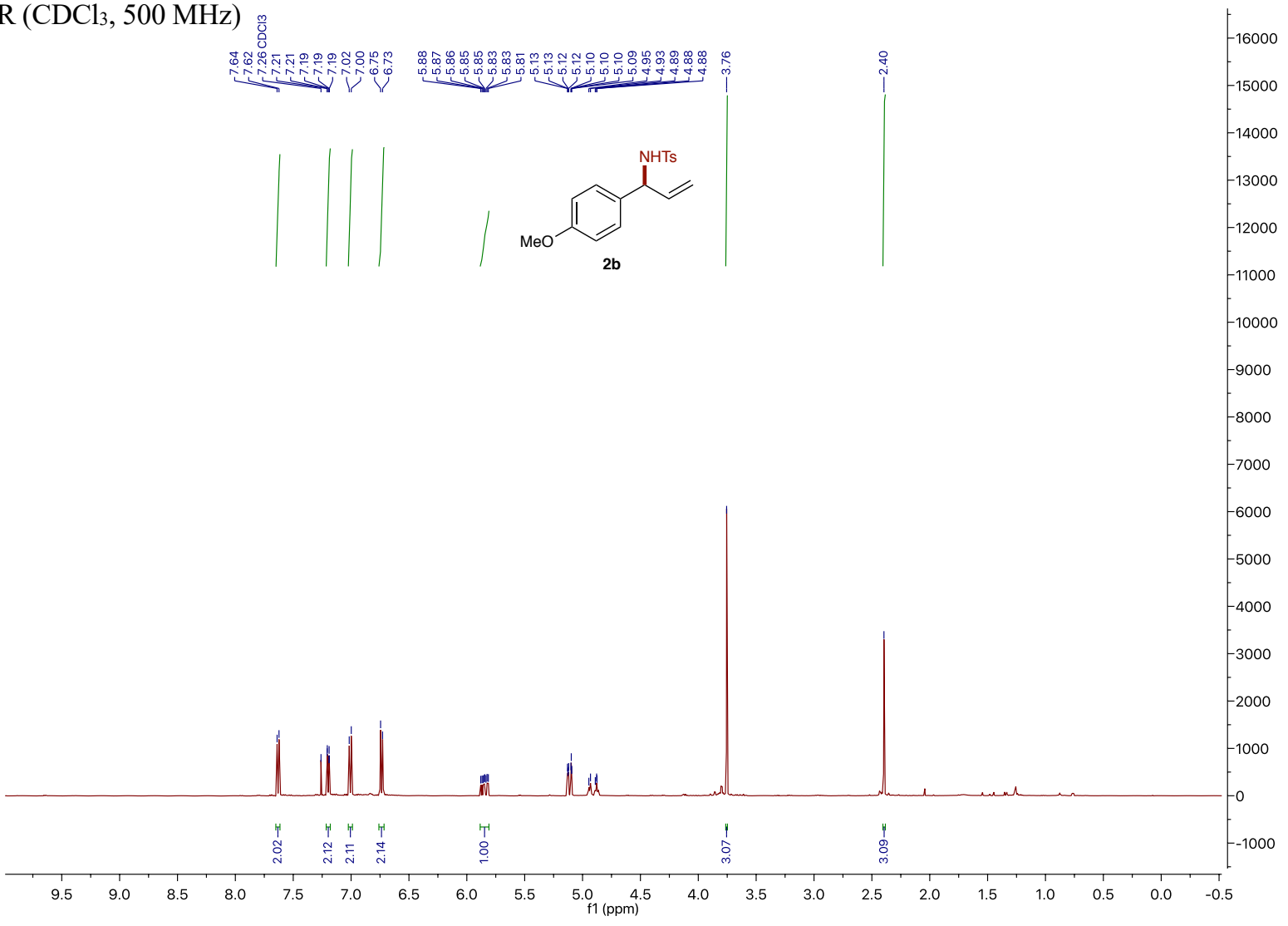




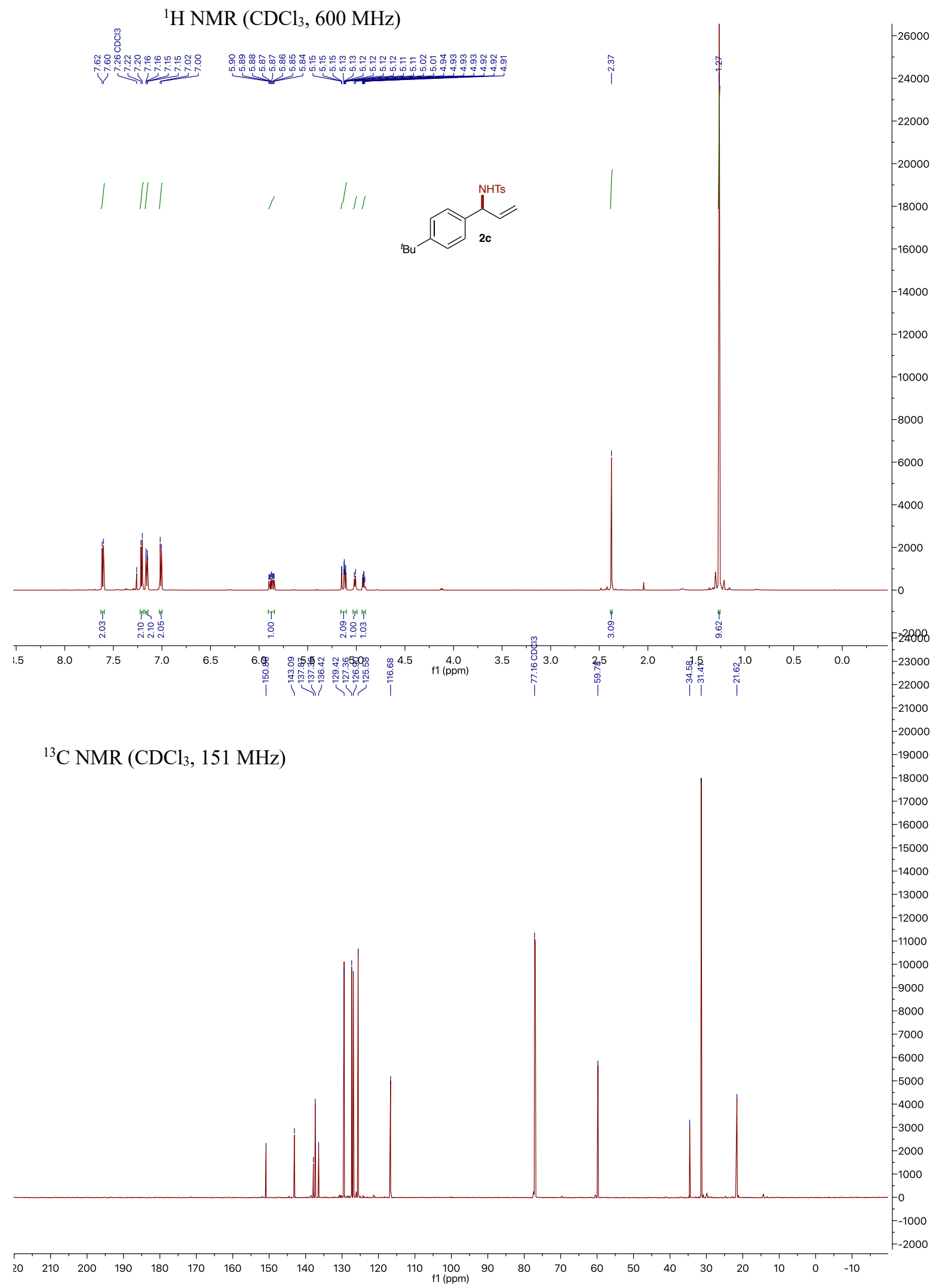


${ }^{1} \mathrm{H} \mathrm{NMR}\left(\mathrm{CDCl}_{3}, 600 \mathrm{MHz}\right)$

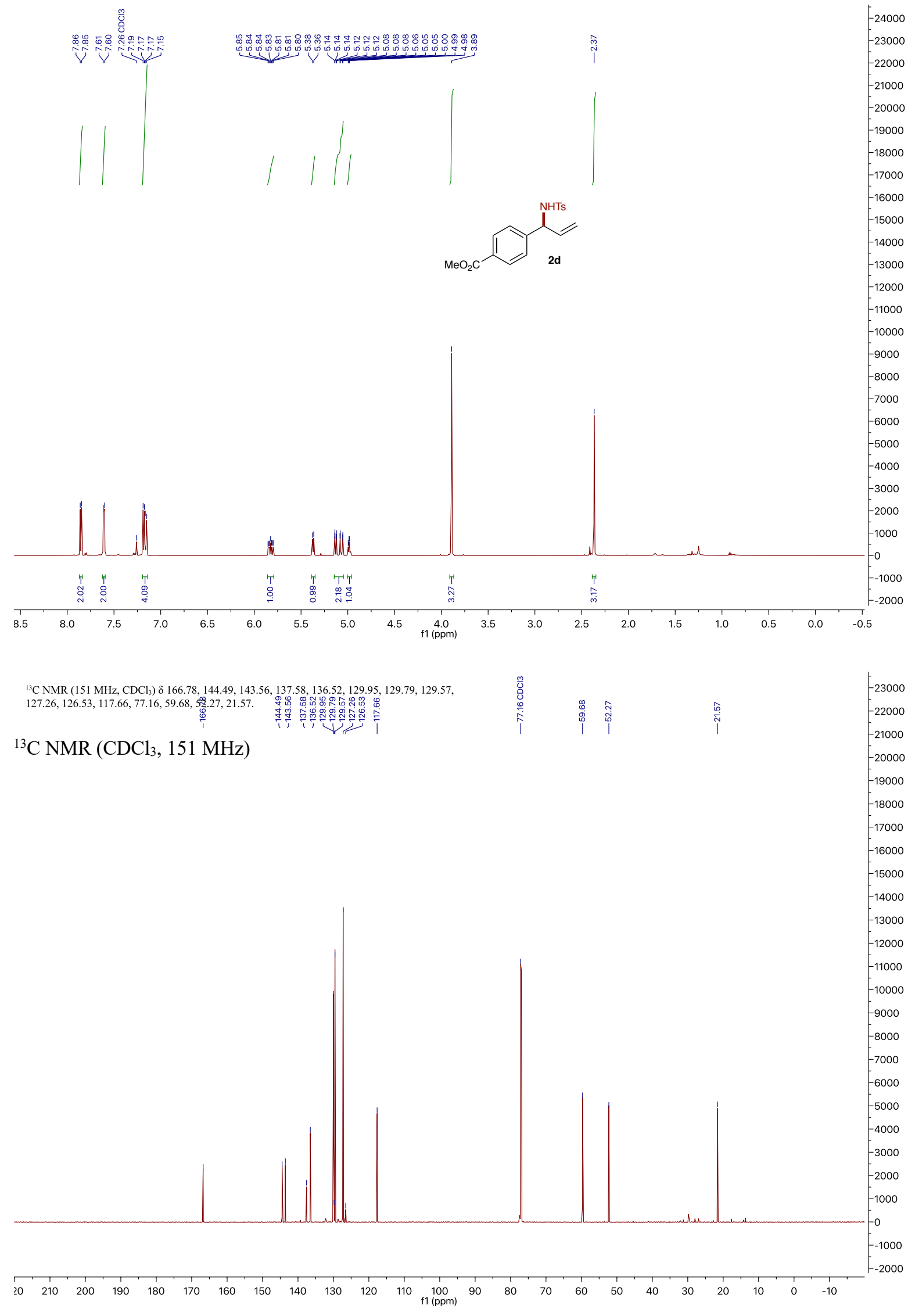


${ }^{1} \mathrm{H} \mathrm{NMR}\left(\mathrm{CDCl}_{3}, 600 \mathrm{MHz}\right)$

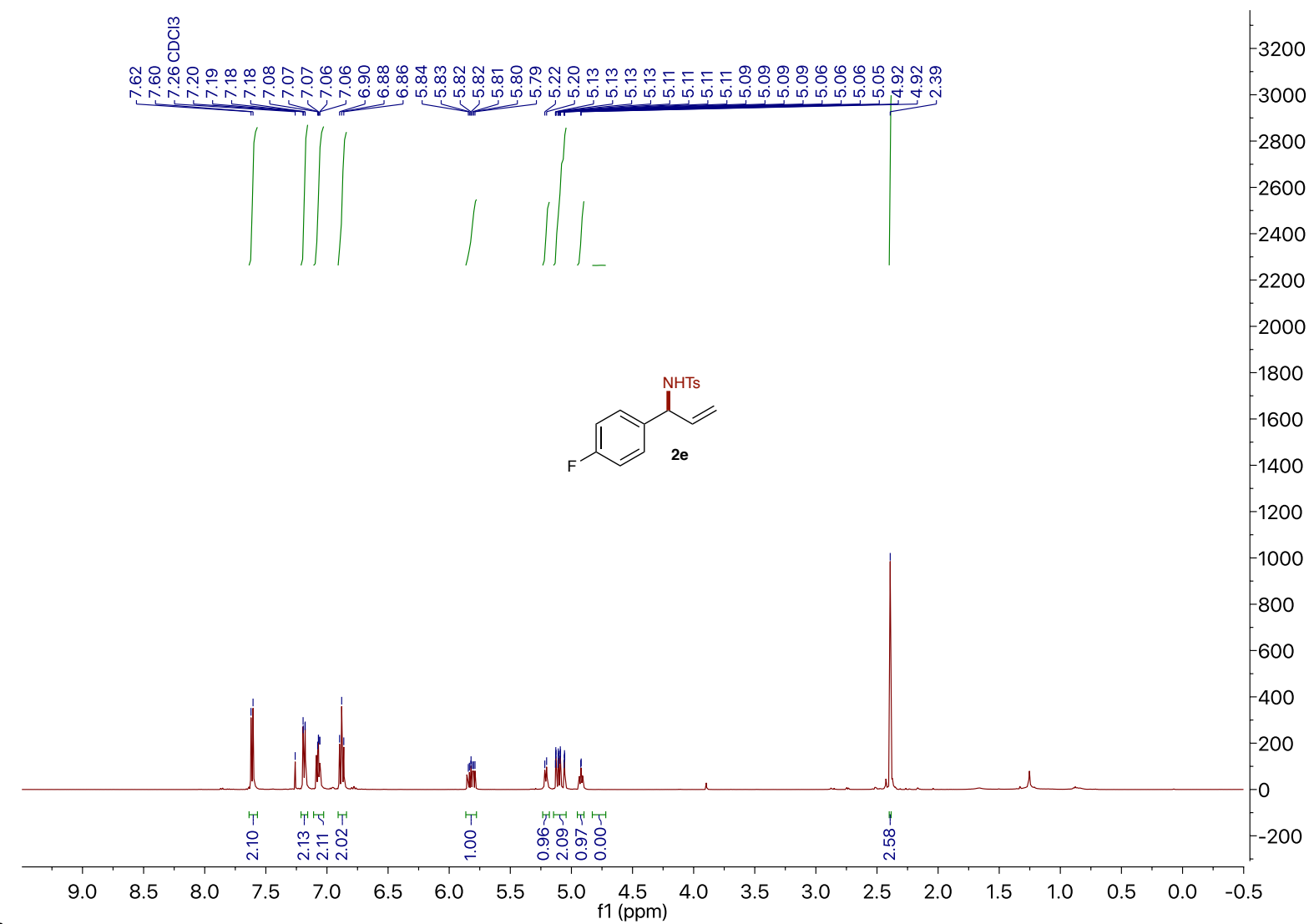

${ }^{13} \mathrm{C} \mathrm{NMR}\left(\mathrm{CDCl}_{3}, 151 \mathrm{MHz}\right)$

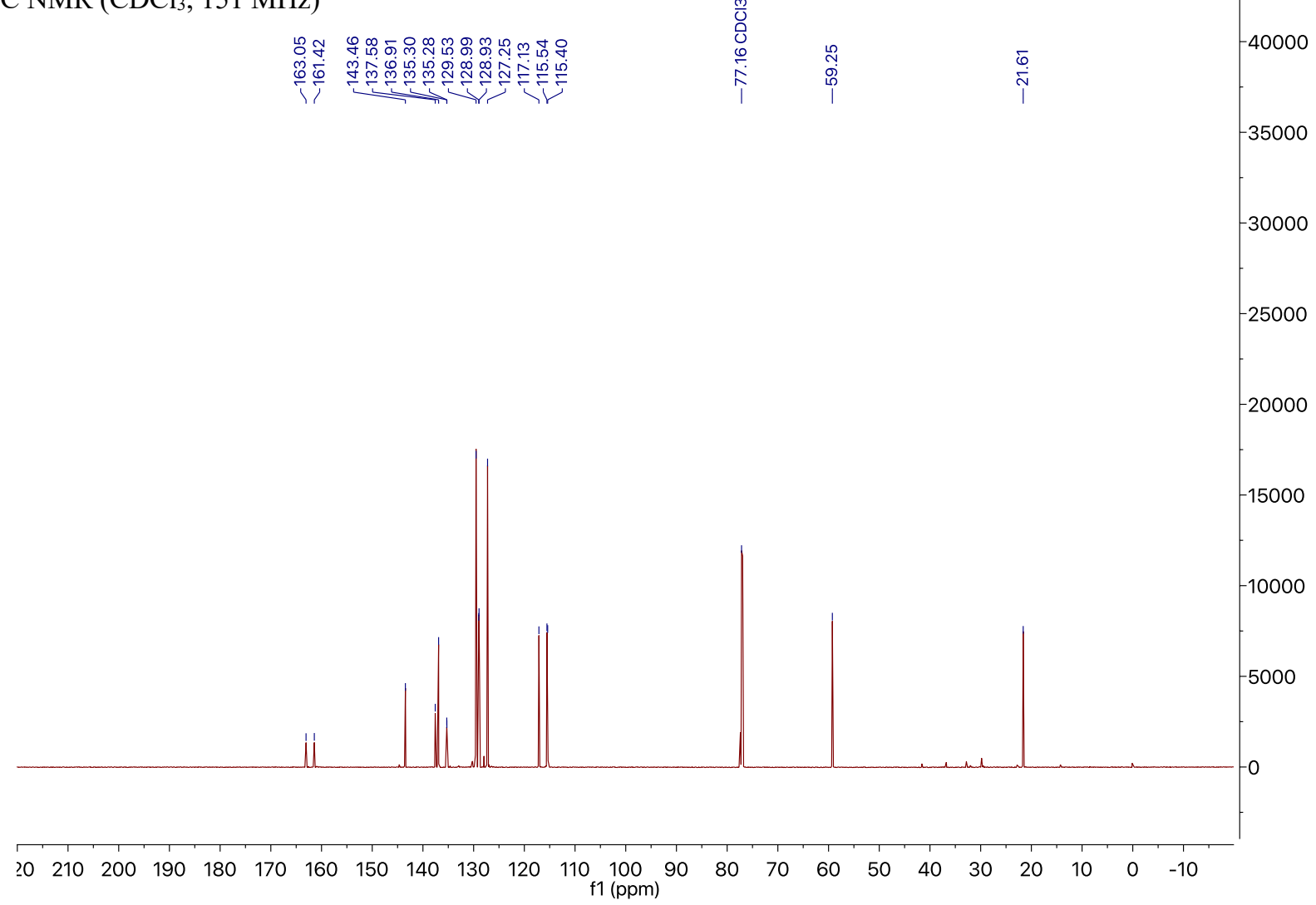




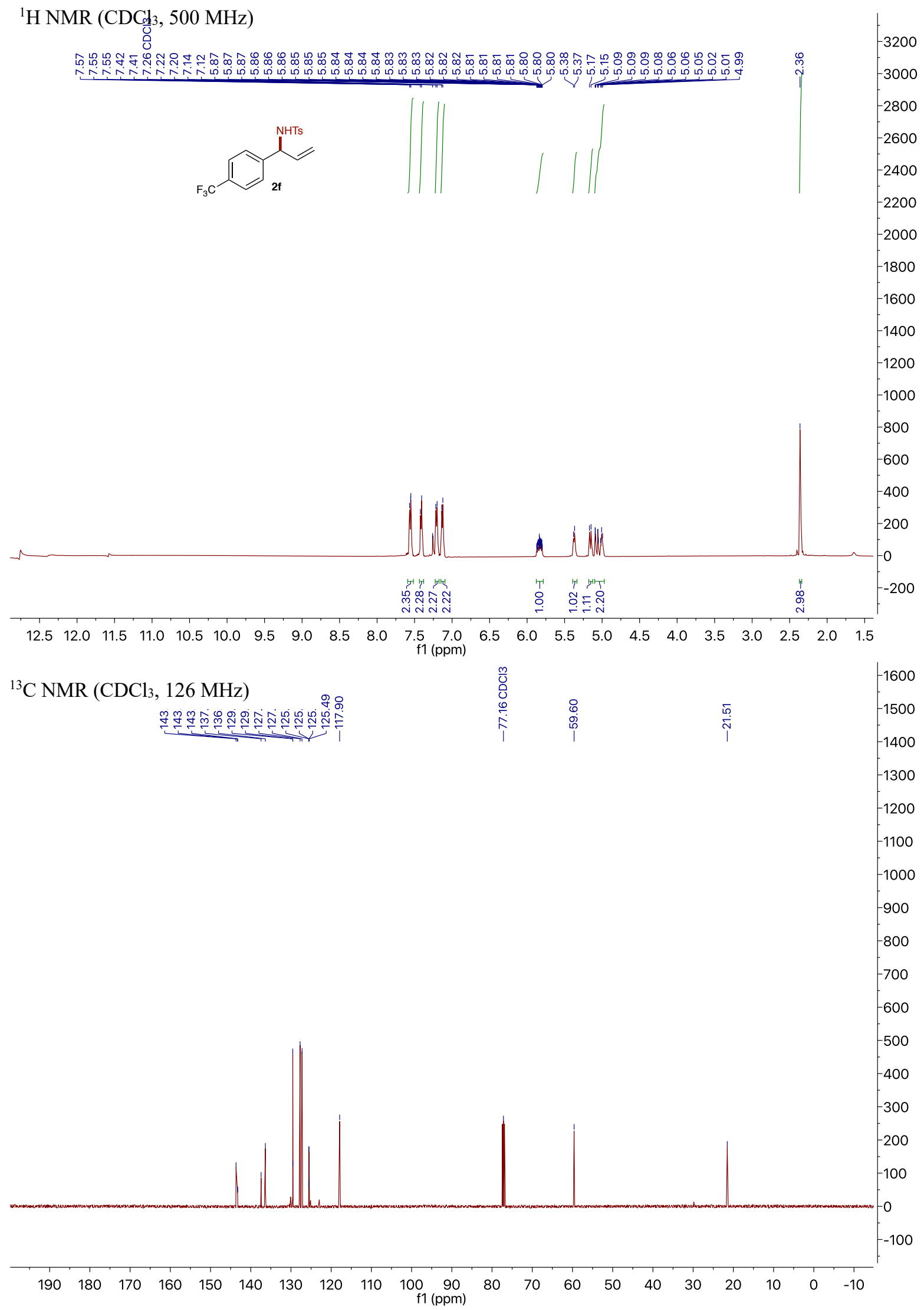




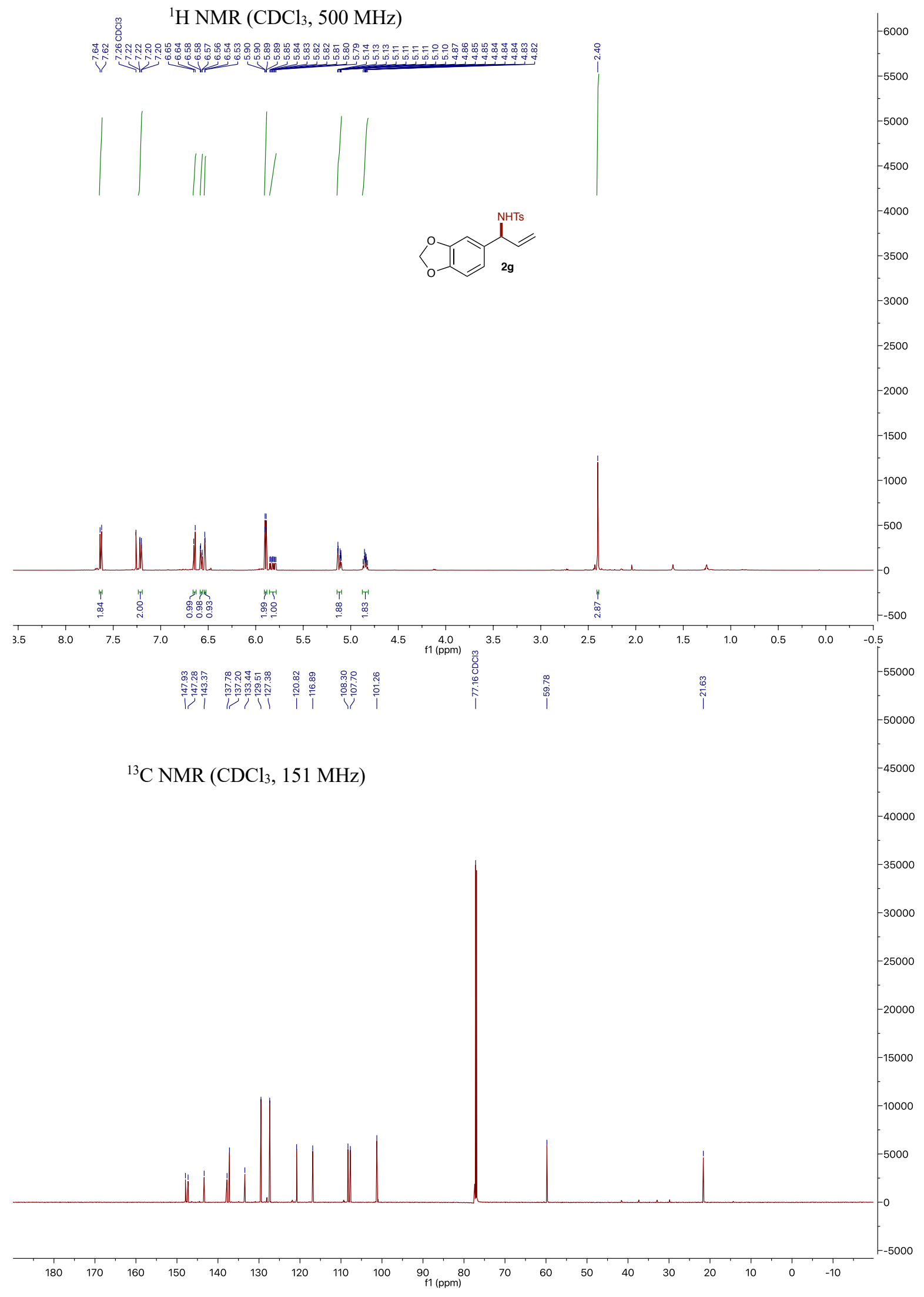


${ }^{1} \mathrm{H} \mathrm{NMR}\left(\mathrm{CDCl}_{3}, 600 \mathrm{MHz}\right)$

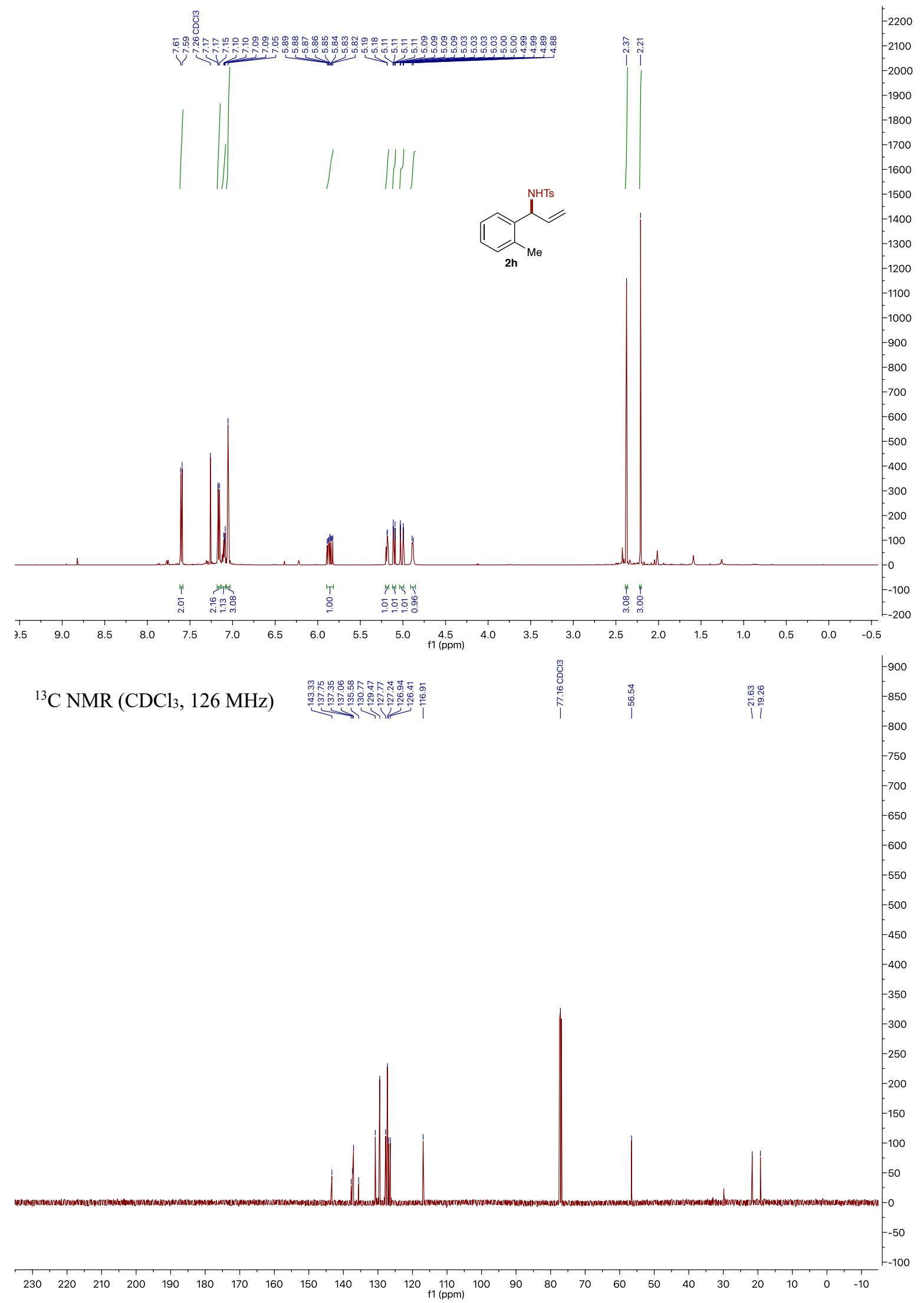




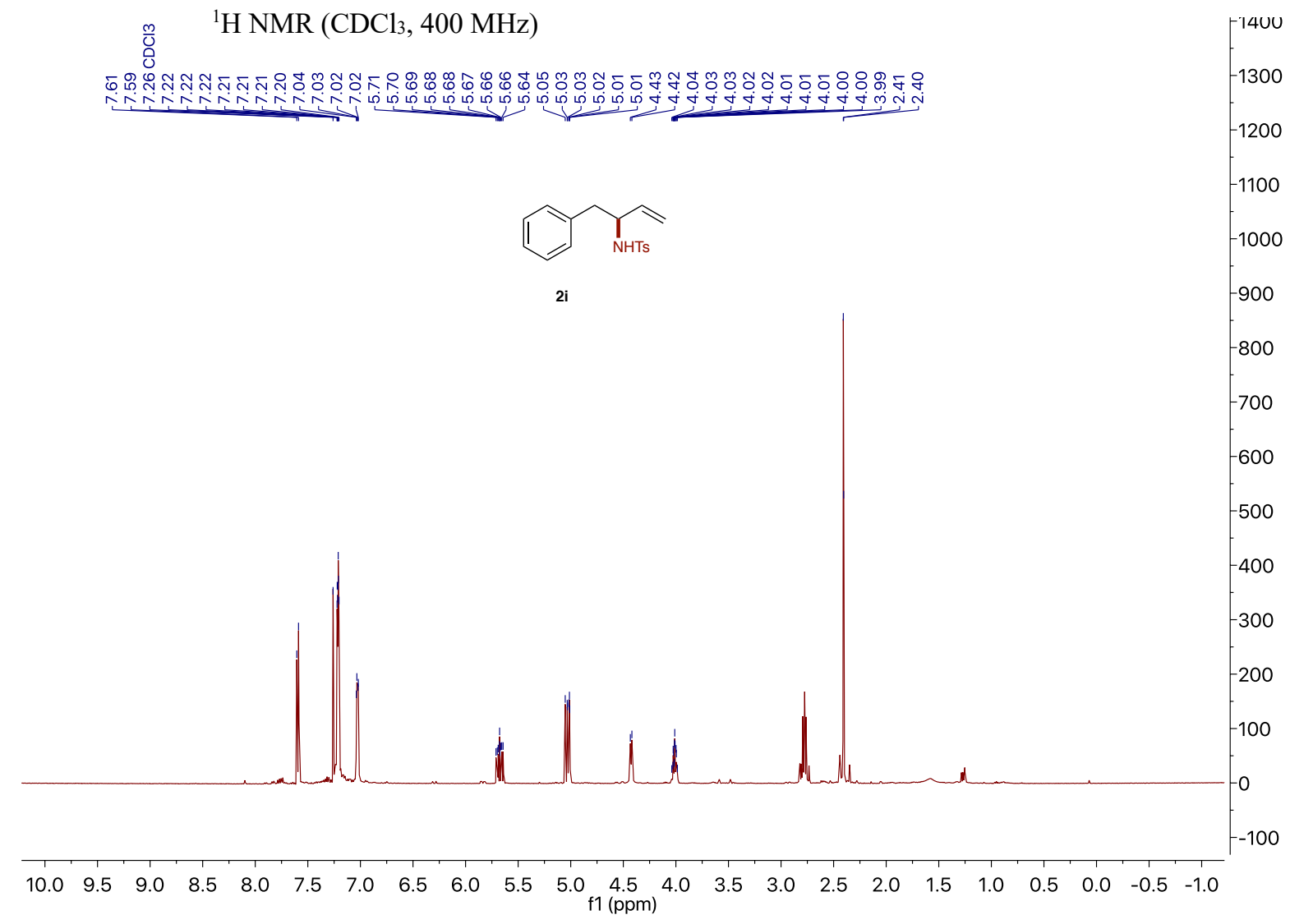


${ }^{1} \mathrm{H}$ NMR $\left(\mathrm{CDCl}_{3}, 400 \mathrm{MHz}\right)$

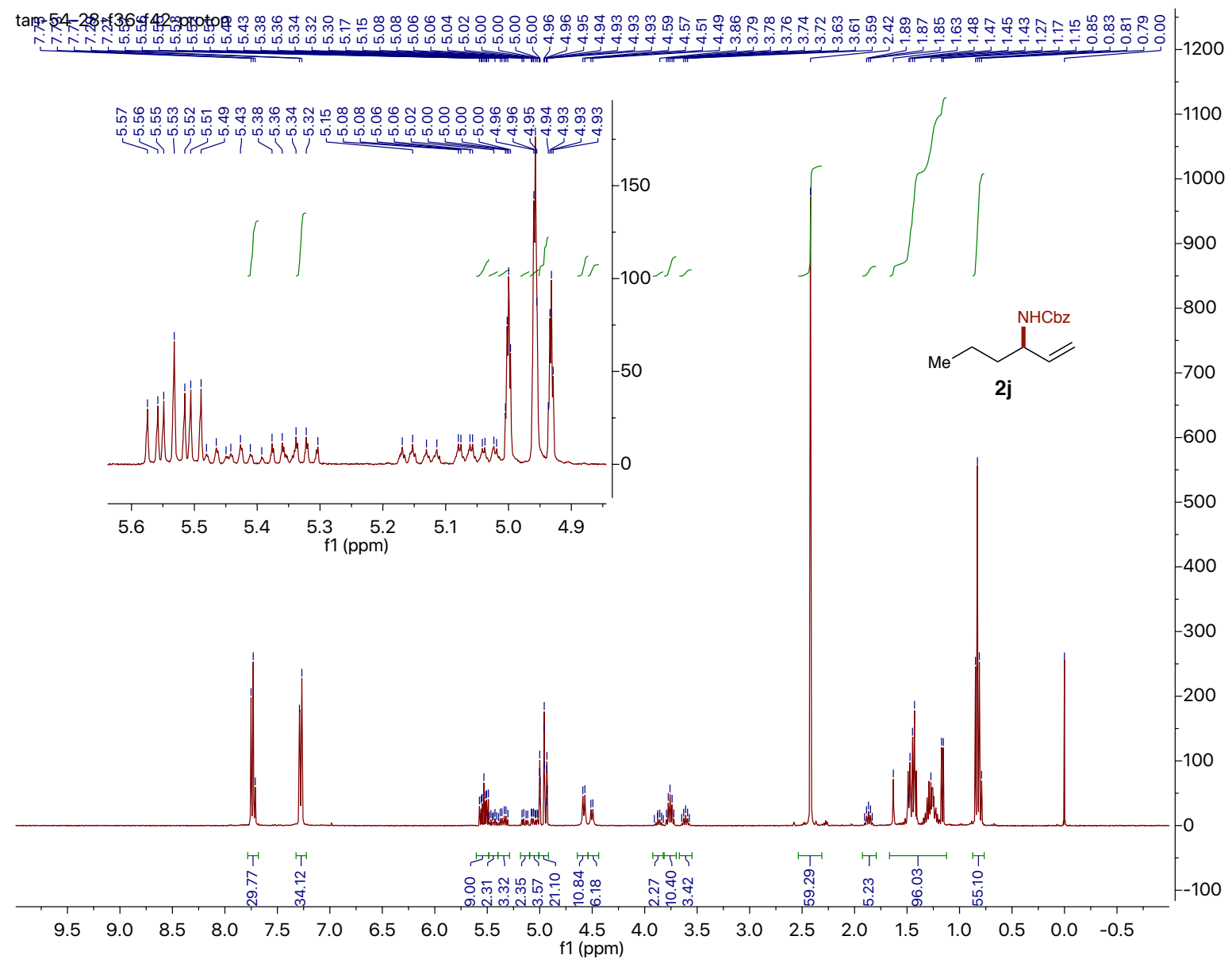


${ }^{1} \mathrm{H} \mathrm{NMR}\left(\mathrm{CDCl}_{3}, 500 \mathrm{MHz}\right)$

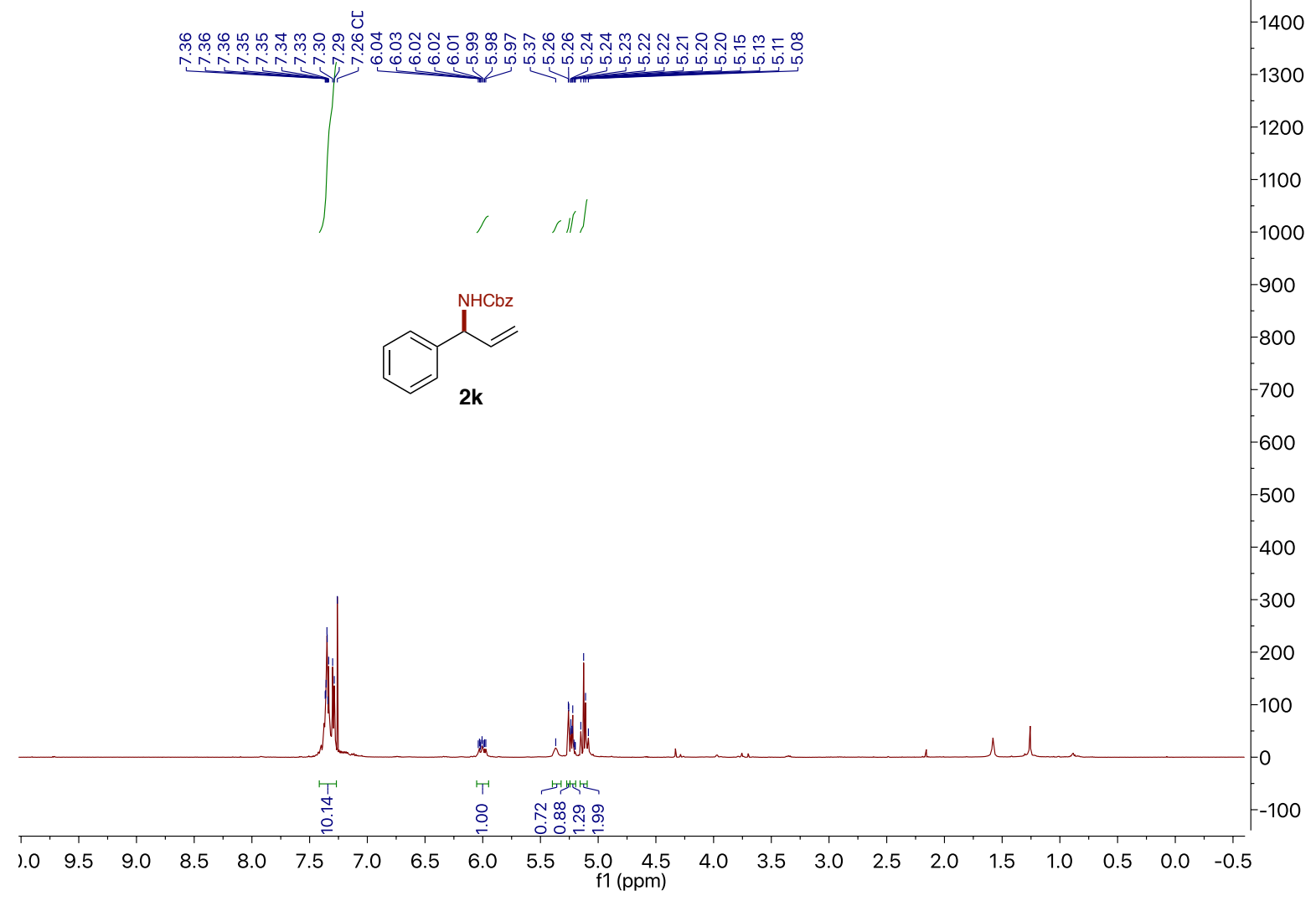


${ }^{1} \mathrm{H} \mathrm{NMR}\left(\mathrm{CDCl}_{3}, 500 \mathrm{MHz}\right)$

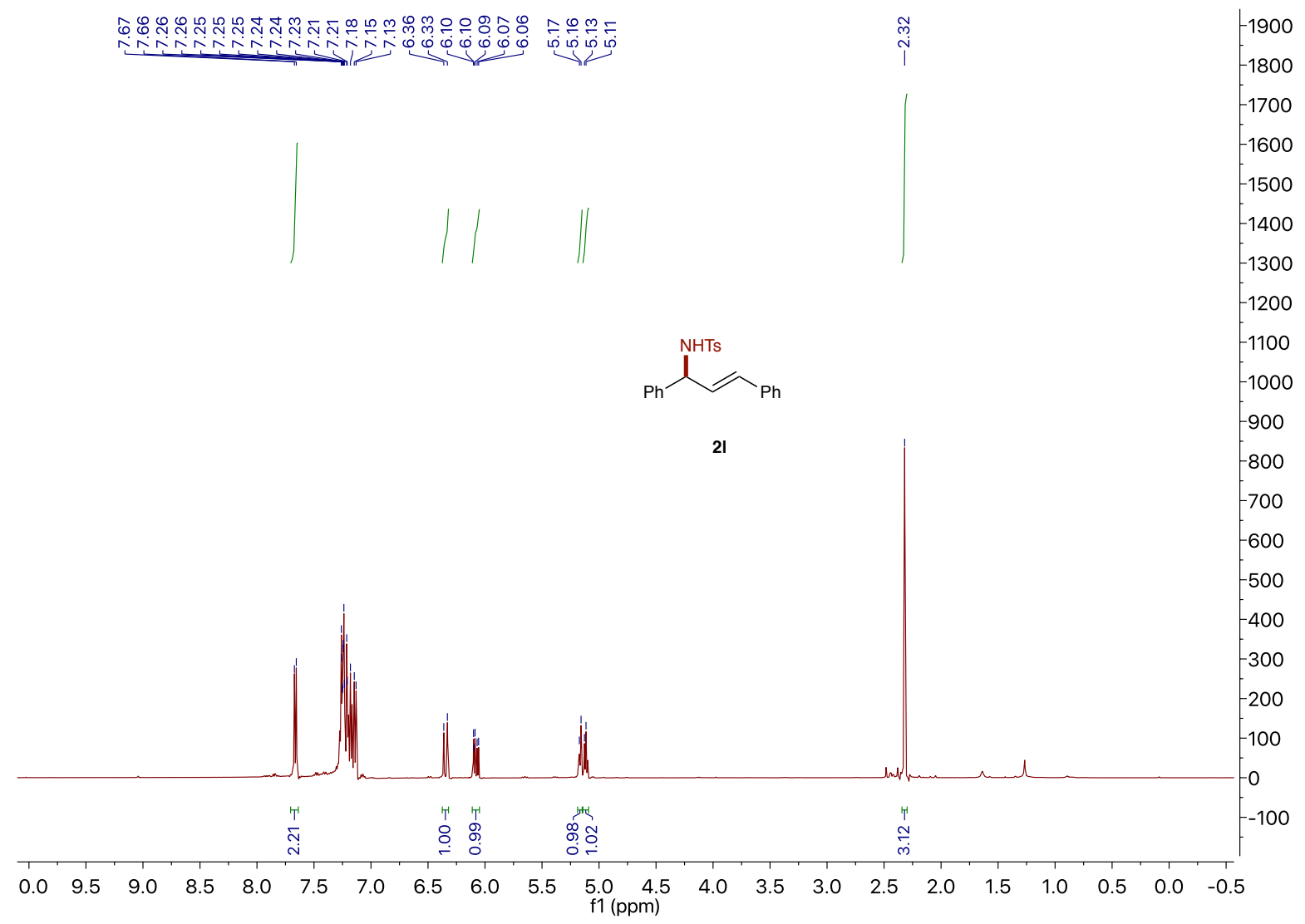




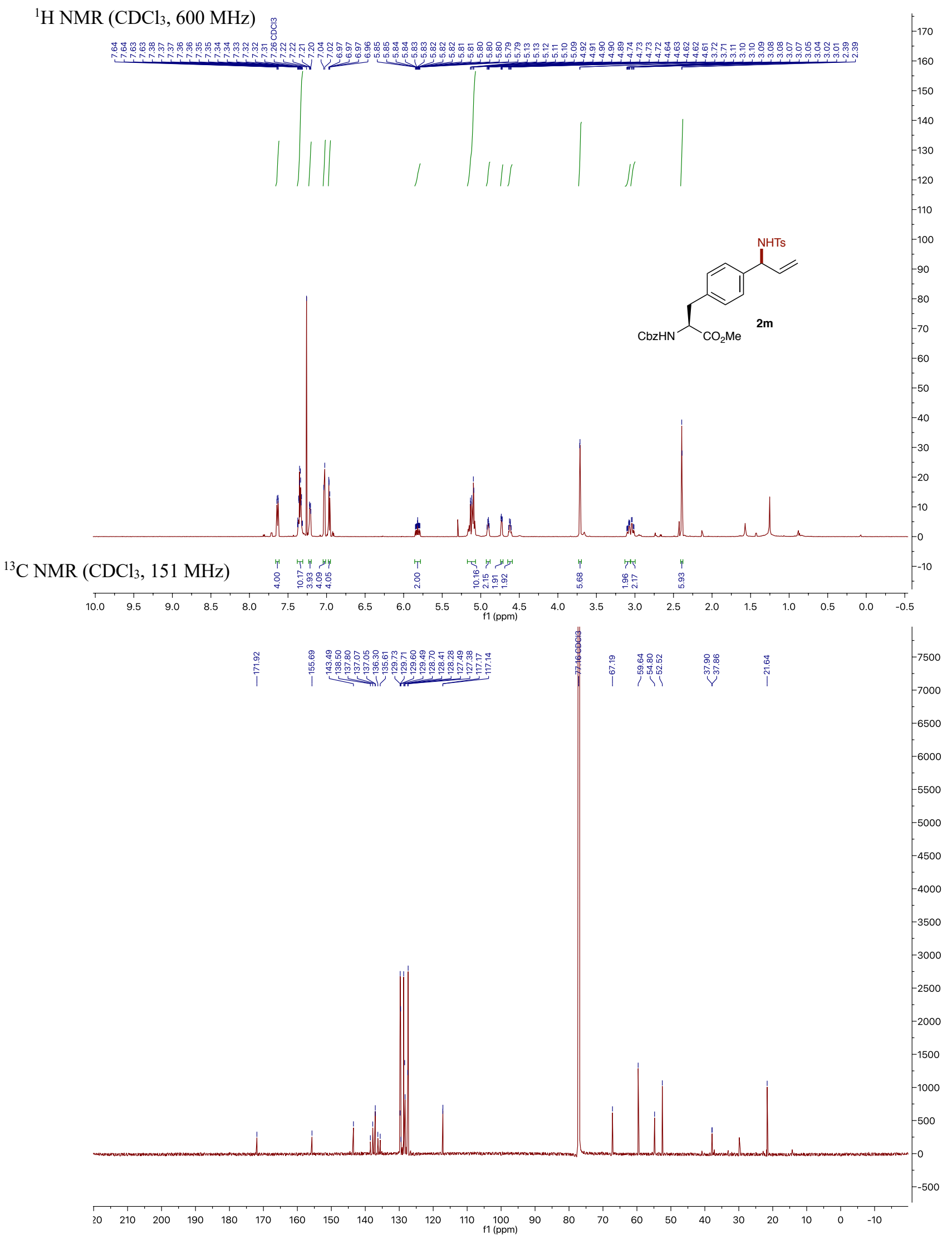




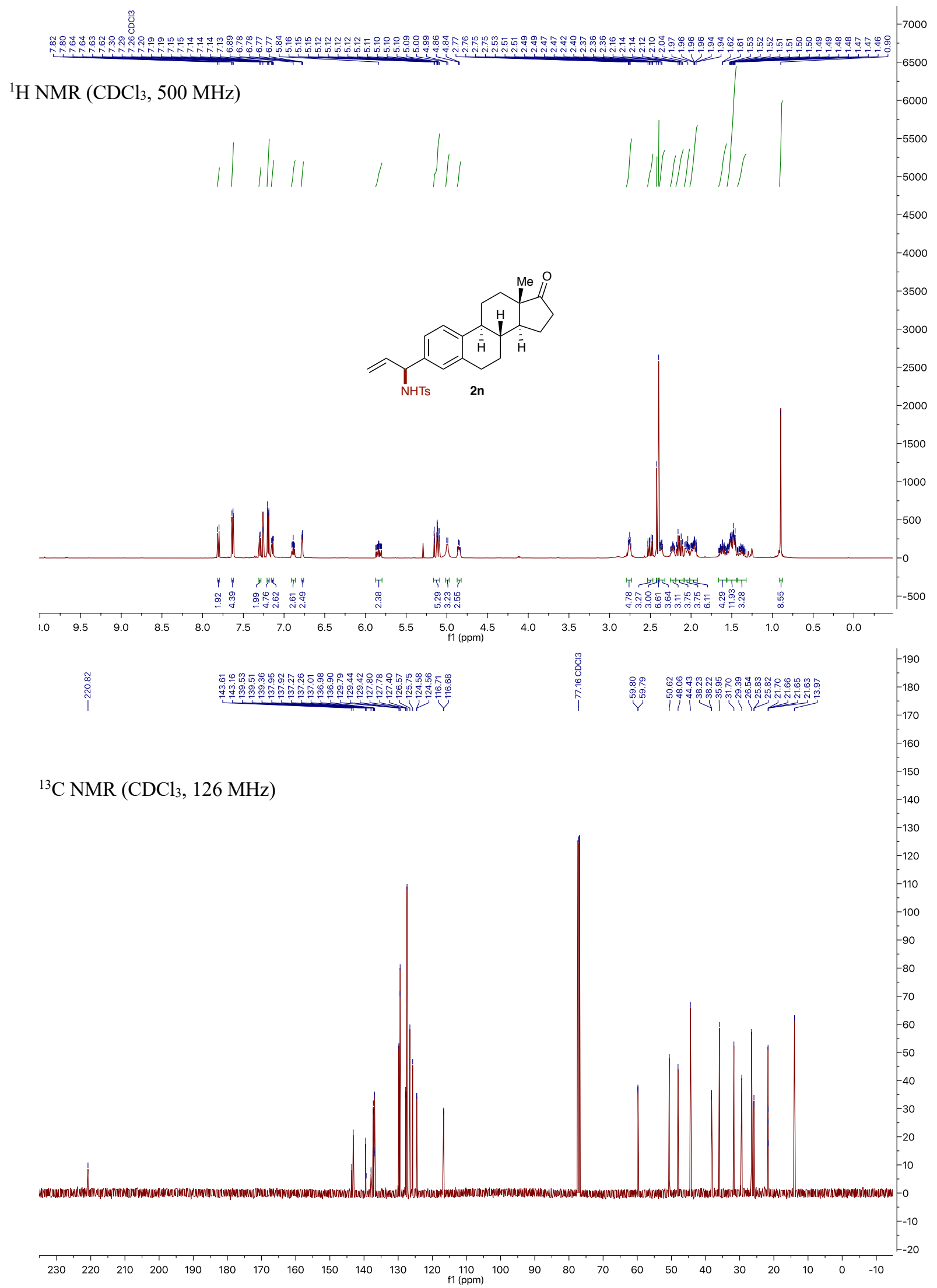


${ }^{1} \mathrm{H} \mathrm{NMR}\left(\mathrm{CDCl}_{3}, 500 \mathrm{MHz}\right)$

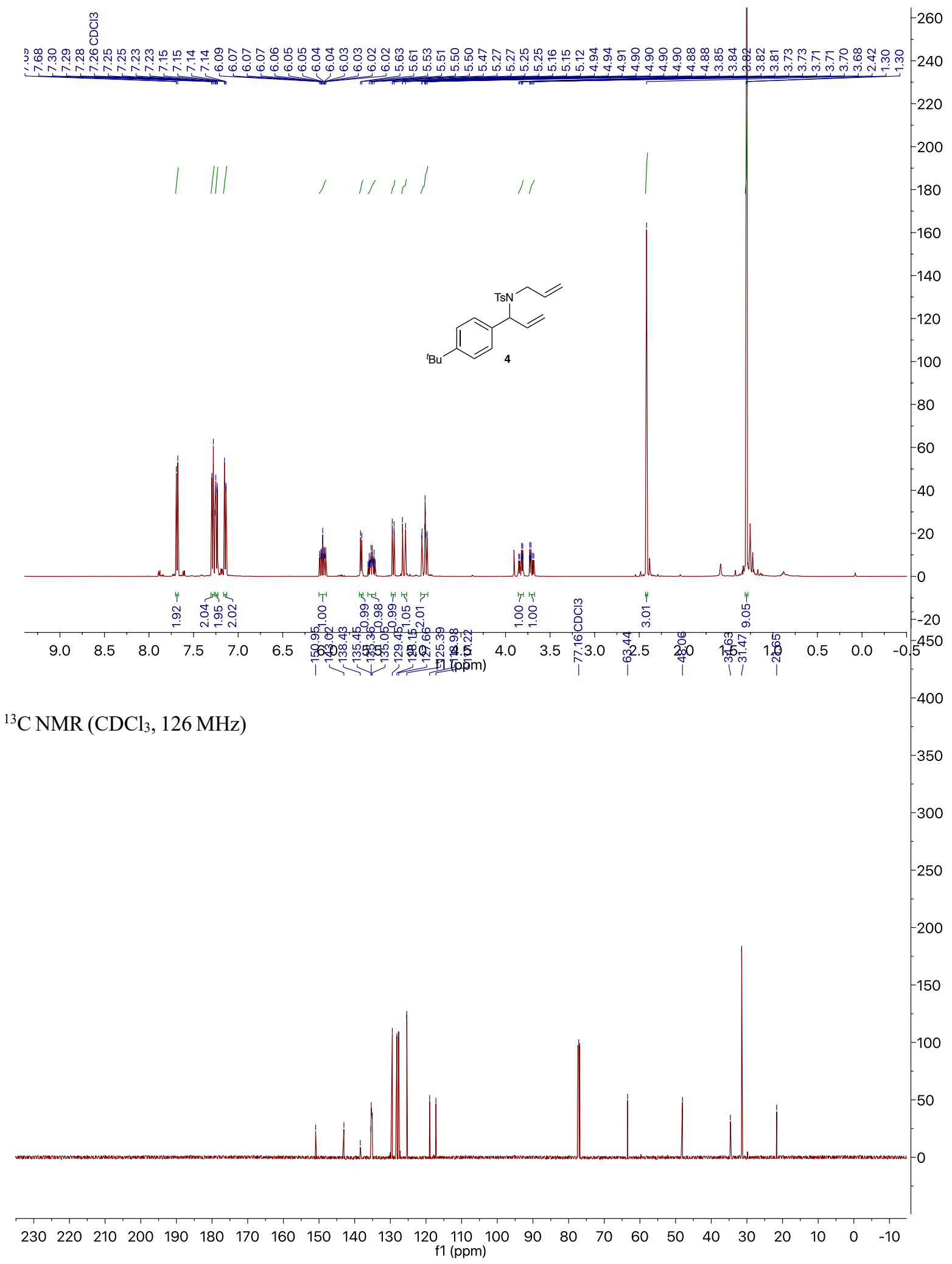




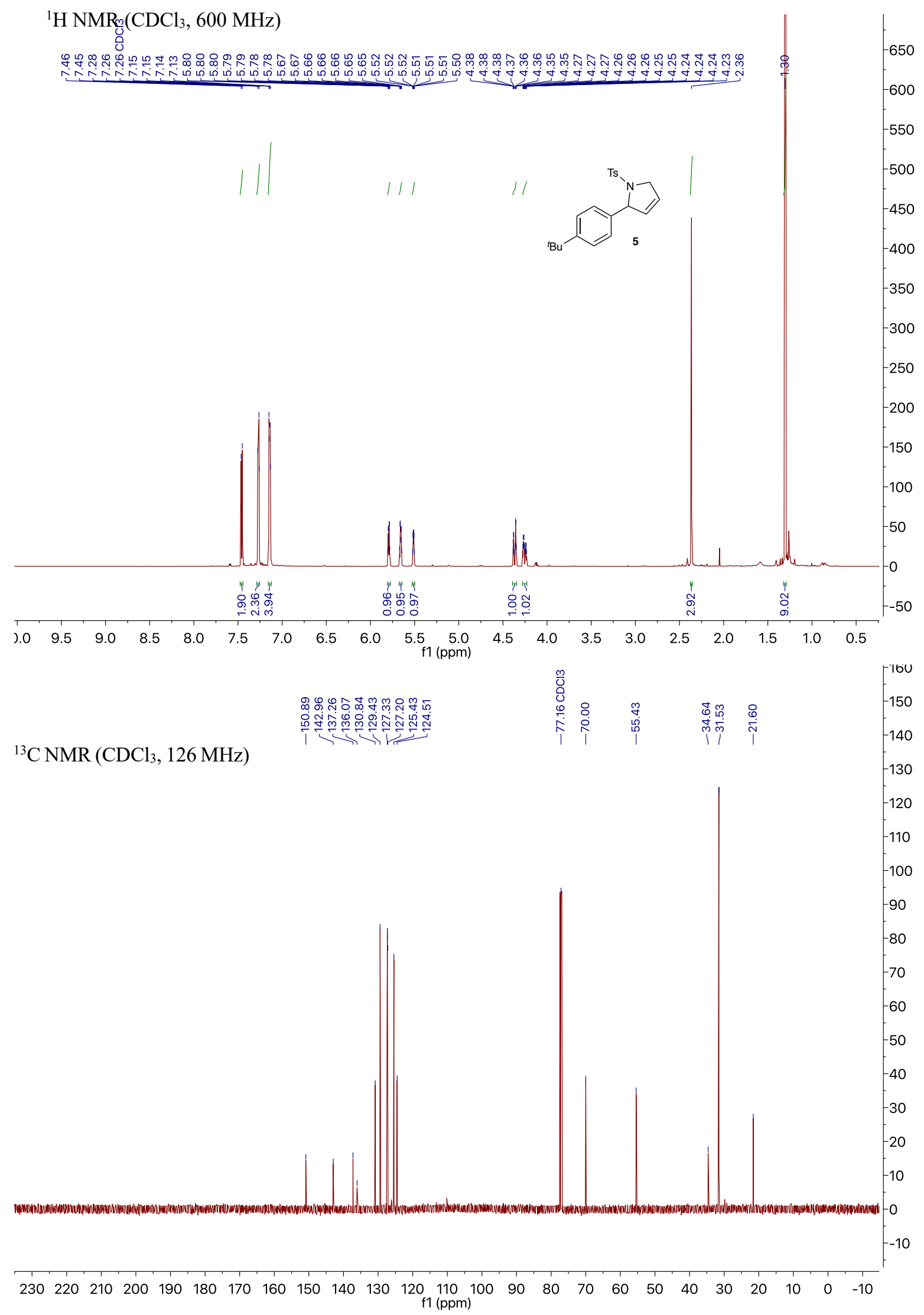


${ }^{1} \mathrm{H} \mathrm{NMR}\left(\mathrm{CDCl}_{3}, 400 \mathrm{MHz}\right)$

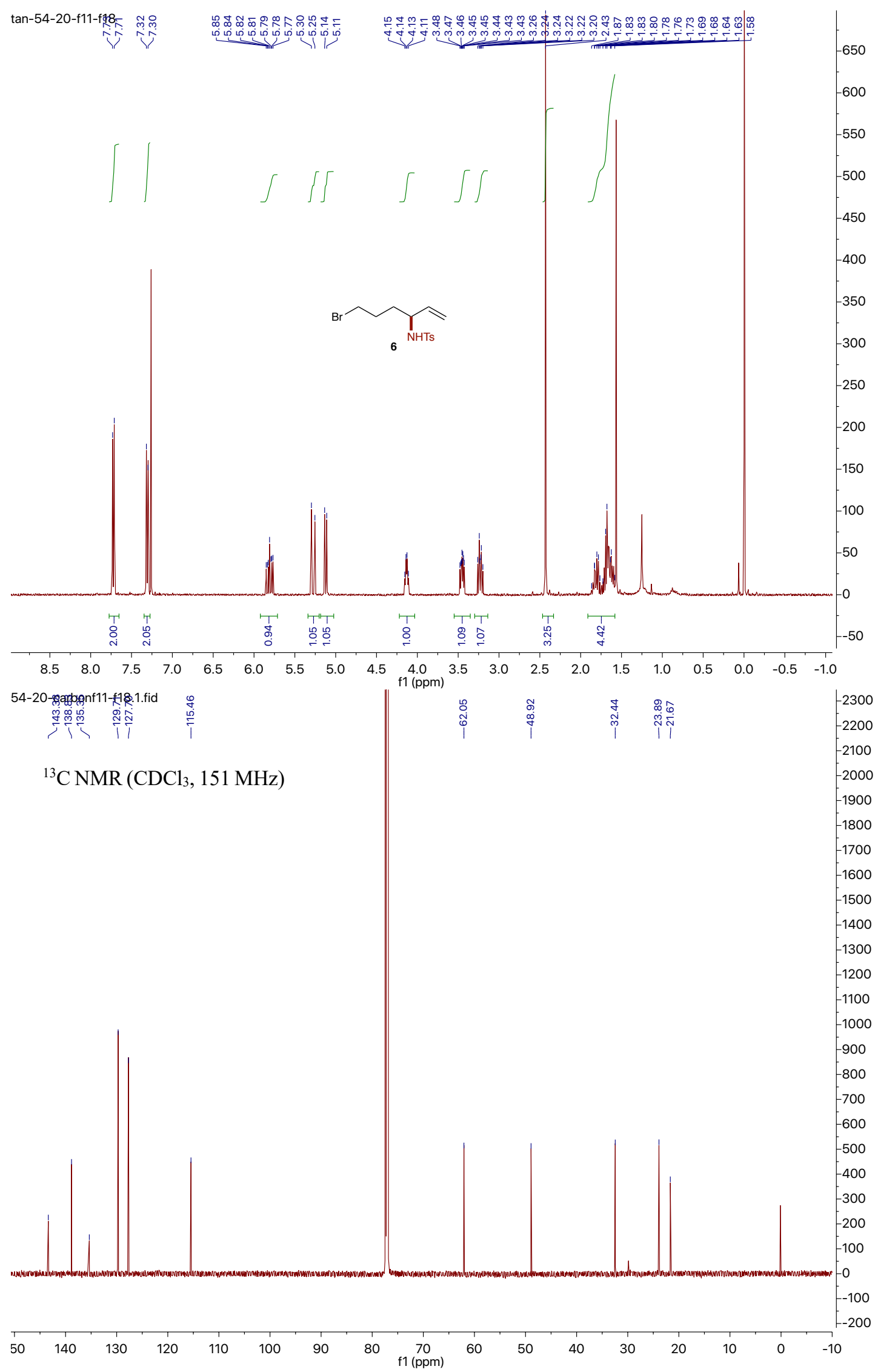




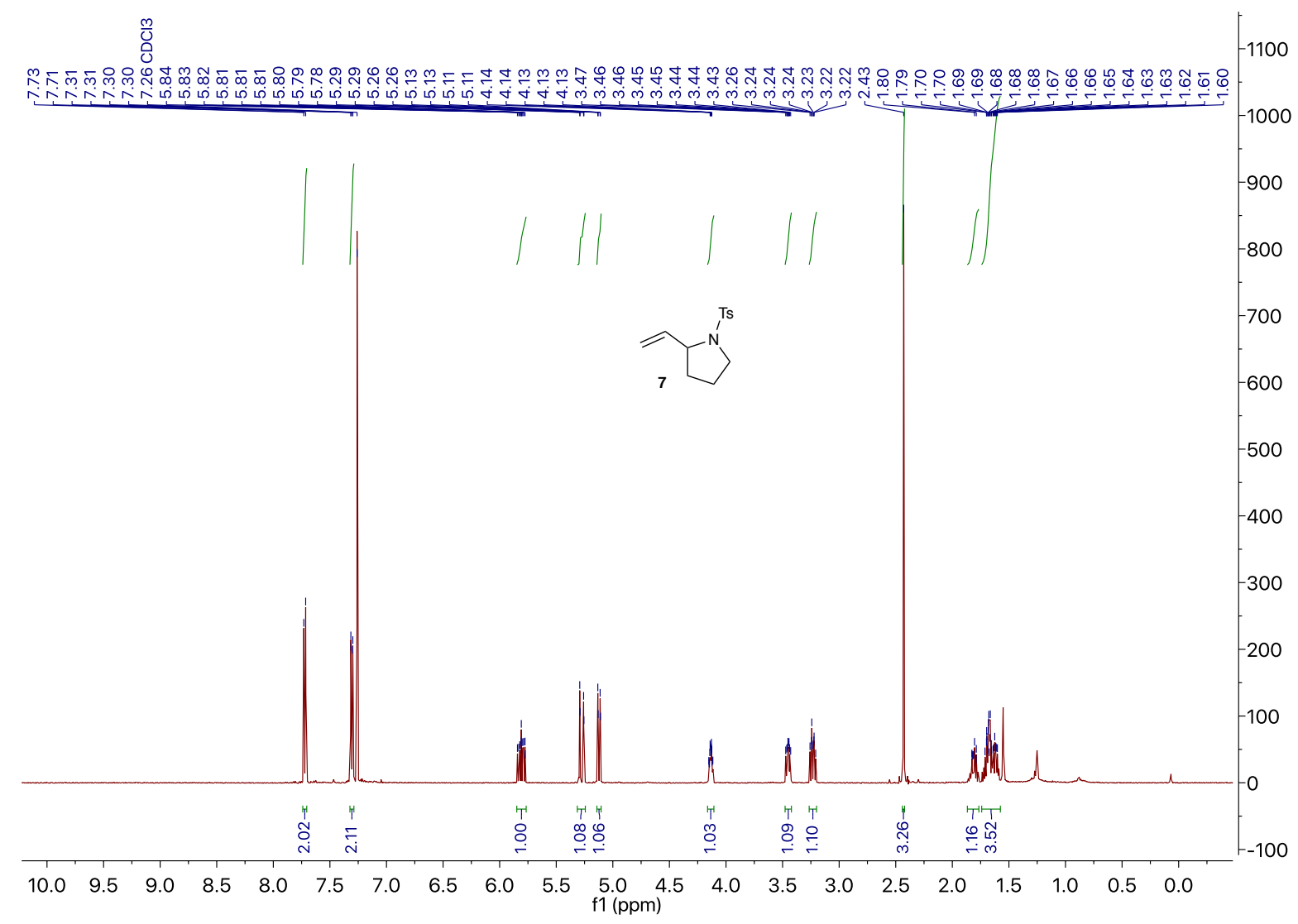

